\title{
Neoplasia de células blásticas dendríticas plasmocitoides com manifestação cutânea exuberante: relato de caso
}

\section{Exuberant skin involvement in blastic plasmacytoid dendritic cell neoplasm: a case report}

\begin{abstract}
Karla Linhares Pinto ${ }^{1}$. José Wilson Accioly Filho². Iago Farias Jorge ${ }^{3}$. André Luís Nunes Avelino ${ }^{4}$. Thatiana Catunda Torres Mota ${ }^{1}$. Amanda Maria Menezes Dantas ${ }^{1}$. Alinne Mota Cavalcante ${ }^{1}$.

1 Médica, residente de Dermatologia, Hospital Universitário Walter Cantídio (HUWC), Universidade Federal do Ceará (UFC), Fortaleza, Ceará, Brasil. 2 Mestre e Doutor em Dermatologia pela Universidade Federal do Rio de Janeiro (UFRJ), Professor Adjunto de Dermatologia da Universidade Federal do Ceará (UFC), Chefe do Serviço de Dermatologia do Hospital Universitário Walter Cantídio (HUWC), Fortaleza, Ceará, Brasil. 3 Médico, Universidade Federal do Ceará (UFC), Fortaleza, Ceará, Brasil. 4 Médico, residente de Patologia, Hospital Universitário Walter Cantídio (HUWC), Universidade Federal do Ceará (UFC), Fortaleza, Ceará, Brasil.
\end{abstract}

\section{RESUMO}

A Neoplasia de células bláticas dendríticas plasmocitoides (NCBDP) é caracterizada pela co-expressão dos marcadores CD4 e CD56, pelo menos um antígeno de células dendríticas e plasmocitoides e ausência de outros marcadores de linhagens hematopoiéticas. Envolvimento cutâneo é a apresentação inicial mais comum. Relata-se o caso de um paciente de 44 anos que apresentava placas e nódulos eritemato-violáceos distribuídos na face, tronco e membros e aumento importante de gânglios em várias cadeias linfonodais. A biópsia e imunohistoquímica de pele e medula óssea foram realizadas e o diagnóstico de NCBDP foi estabelecido. O paciente realizou quimioterapia com remissão completa do quadro. Nesse cenário, o dermatologista deve estar ciente do seu papel no diagnóstico precoce dessa doença.

Palavras-chave: Antígenos CD4. Antígenos CD56. Infiltração leucêmica.

\section{ABSTRACT}

Blastic plasmacytoid dendritic cell neoplasm (BPDCN) is characterized by coexpression of CD4 and CD56, at least one plasmacytoid dendritic cells antigens and the absence of other markers of hematopoietic lineages. Cutaneous involvement is the most common initial presentation. Here we report the case of a 44-year-old male patient who presented erythematous-violaceous plaques and nodules distributed on face, trunk and limbs as well as significant increase in size of nodes in several lymph nodes chains. After biopsy and immunohistochemical study of the skin and bone marrow, the diagnose of a BPDCN was established. The patient underwent chemotherapy and achieved complete remission. In this scenario the dermatologist should be aware of their role in the identification and early diagnosis of this disease.

Keywords: Antigens CD4. Antigens CD56. Leukemic infiltration.

Autor correspondente: Karla Linhares Pinto, Rua Almirante Rufino, 1450, bloco Jatobá, apartamento 501, Montese, Fortaleza, Ceará. CEP: 60420-312.Telefone: +55 85 98174-0318. E-mail: karla.linhares@yahoo.com.br

Conflito de interesses: Não há qualquer conflito de interesses por parte de qualquer um dos autores.

Recebido em: 05 Jan 2017; Revisado em: 21 Mai 2017; Aceito em: 21 Mai 2017. 


\section{INTRODUÇÃO}

Neoplasia de células blásticas dendríticas plasmocitoides (NCBDP) é uma neoplasia hematopoiética rara derivada de precursores de células dendríticas plasmocitoides, sendo caracterizada pela co-expressão dos marcadores CD4 e CD56 e ausência de outros marcadores específicos de linhagens hematopoiéticas. A exata incidência dessa doença é desconhecida, mas estima-se que represente aproximadamente 0,7\% dos linfomas primários cutâneos. ${ }^{1}$ A NCBDP tem sido descrita em todas as raças por todo o mundo, apresentando leve predominância no sexo masculino. A idade média de acometimento ocorre entre 60 e 70 anos embora possa se apresentar em qualquer idade, inclusive na infância., ${ }^{2,3}$

Envolvimento cutâneo é a apresentação inicial mais comum dessa neoplasia e inclui nódulos e placas eritemato-violáceos isolados ou generalizados. Associados às manifestações cutâneas, pode haver acometimento de outros órgãos como linfonodos, medula óssea e sistema nervoso central. O curso dessa neoplasia é altamente agressivo independentemente da apresentação inicial e apesar disso, devido a raridade e o recente reconhecimento como uma doença com caraterísticas próprias, não há um protocolo de tratamento bem estabelecido. ${ }^{1,3,4}$

No presente relato, descrevemos um caso de NCBDP com manifestação cutânea exuberante, apresentando boa resposta inicial ao tratamento com o protocolo CALGB (Grupo de Câncer e Leucemia B) e sobrevida acima da expectativa para a doença.

\section{RELATO DO CASO}

Paciente do sexo masculino, 44 anos, relatou que aproximadamente 5 meses antes da primeira consulta em nosso serviço apareceram lesões cutâneas envolvendo tronco e dorso que, posteriormente, se estenderam para face e porção proximal dos membros superiores e inferiores. Após início dessas lesões, ele desenvolveu náuseas, vômitos, astenia, febre diária, perda de peso não quantificada e aumento de gânglios. Ao exame físico apresentava placas e nódulos eritemato-violáceos distribuídos na face, tronco e membros (Figuras 1 e 2) associados ao aumento importante de linfonodos, caracterizados por serem de consistência pétrea, aderidos uns aos outros e a planos profundos, nas cadeias cervicais posteriores, submandibulares, submentoniana, inguinais, epitrocleares, retroauricular e axilares.

O hemograma completo evidenciou pancitopenia e no esfregaço de sangue periférico foram encontrados eritroblastos e leucoblastos. A biópsia cutânea revelou um denso infiltrado de células de tamanho médio, cromatina fina e citoplasma escasso localizado em derme reticular (Figura 3) e a imuno-histoquímica mostrou positividade para CD4 e CD56 (Figura 4) e TDT assim como negatividade para CD3, CD5, CD8, CD20, CD34, CD117 e mieloperoxidase, com índice de proliferação (Ki-67) de $80 \%$. A imunofenotipagem da biópsia de medula óssea evidenciou $80,3 \%$ de células blásticas que não expressavam antígenos definitivos de linhagem linfoide ou mieloide, com positividade para CD4, CD33, CD38, CD56, CD123 e HLA-DR.
Baseado em dados clínicos e laboratoriais, o paciente foi diagnosticado com NCBDP. As tomografias de tórax, abdome e pelve evidenciaram extenso acometimento linfonodal nessas regiões e a análise do líquor cefalorraquidiano não evidenciou células neoplásicas.

O paciente foi encaminhado para o serviço de hematologia onde iniciou quimioterapia com protocolo CALGB, que inclui as drogas prednisona, vincristina, daunorrubicina, L-asparaginase, metotrexate, ciclofosfamida, citarabina, mercaptopurina e mitoxantrone. Após 2 meses do início do tratamento o paciente evoluiu com remissão completa da neoplasia por critérios clínico e laboratorial, sendo então sugerido o transplante de medula óssea, o qual o paciente recusou por motivos pessoais. Apesar disso o paciente se mantém em remissão após 17 meses do início do tratamento (Figura 5).

Figura 1. Placas eritemato-violáceas infiltradas na face.

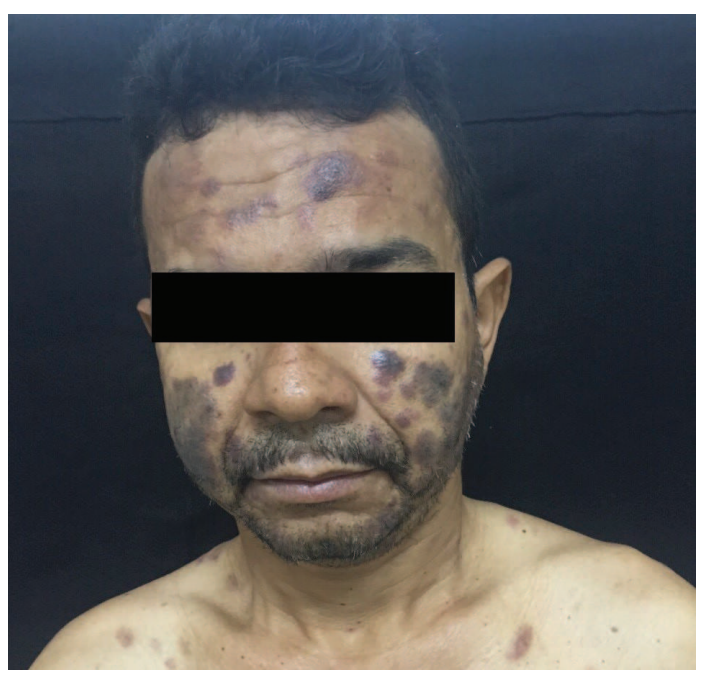

Figura 2. Placas e nódulos eritemato-violáceas infiltrados no tronco e nos membros superiores.

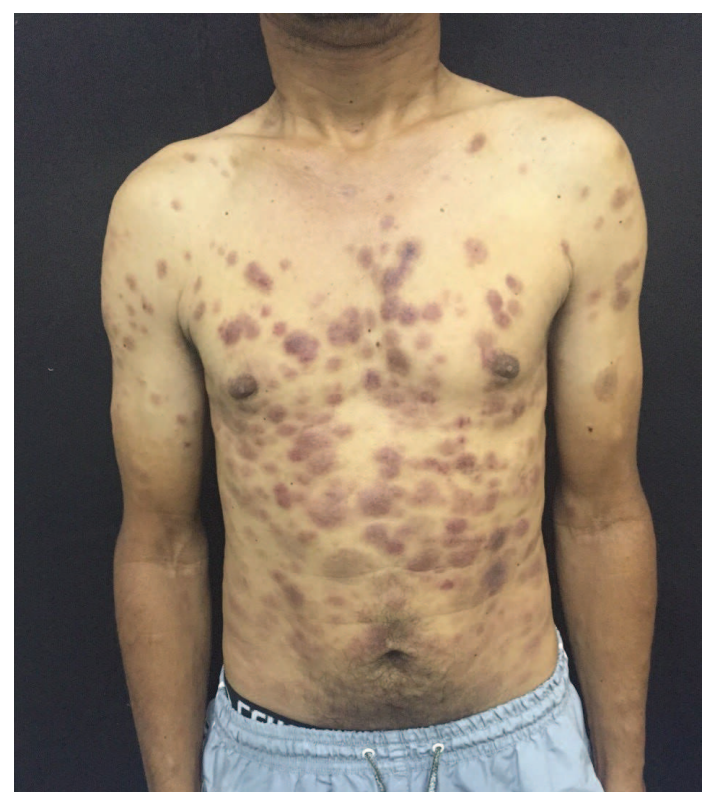


Figura 3. Infiltrado de células de tamanho médio com cromatina fina e citoplasma escasso dissecando o colágeno.

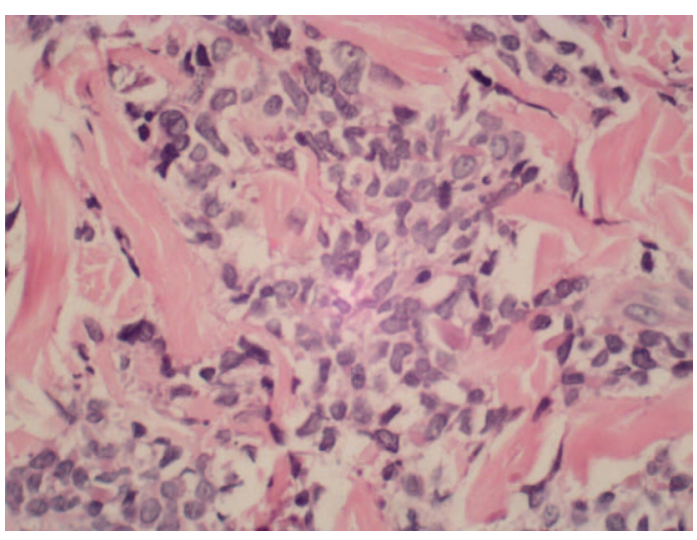

Figura 4. Infiltrado difusamente positivo para CD56.

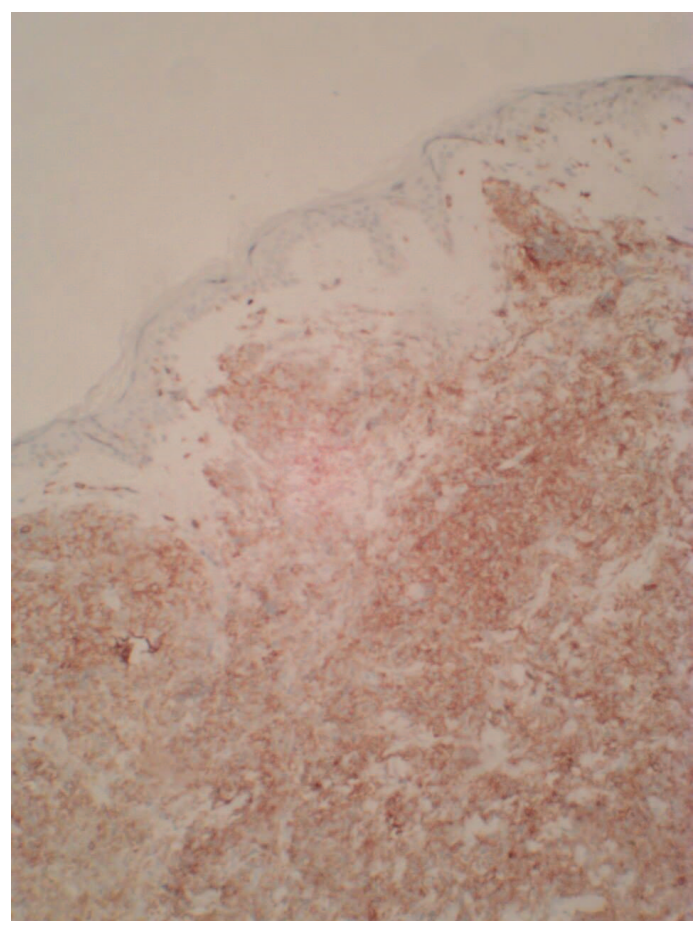

Figura 5. Máculas hipercrômicas de aspecto residual no tronco e nos membros superiores.

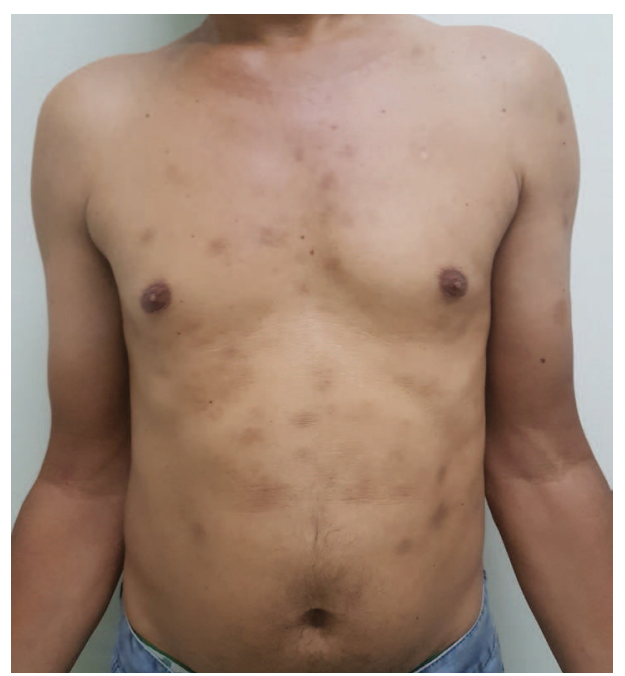

\section{DISCUSSÃO}

A NCBDP é um tipo raro e altamente invasivo de malignidade hematopoiética que acomete principalmente homens idosos. ${ }^{2}$ Embora manifestações cutâneas sejam a principal forma de apresentação inicial dessa doença, lesões cutâneas disseminadas, como no caso relatado, são encontradas em apenas $15 \%$ das vezes. ${ }^{2}$

A completa investigação dos pacientes com essa neoplasia inclui avaliação do sangue periférico através da hematoscopia, da medula óssea através da biópsia e dos linfonodos através de tomografias de tórax, abdome e pelve. Há acometimento de linfonodos em 38\% dos casos, infiltração de medula óssea em $37 \%$, de sangue periférico em $24 \%$ e de sistema nervoso central em $11 \% .{ }^{3} \mathrm{O}$ paciente do relato em questão apresentava múltiplas cadeias linfonodais com características clínicas sugestivas de neoplasia, blastos em sangue periférico, não havia evidências de infiltração neoplásica do sistema nervoso central e biópsia de medula óssea apresentava $80,3 \%$ de células blásticas, sendo essa última característica definidora do quadro de leucemia, na qual são necessários $20 \%$ de blastos como critério diagnóstico. ${ }^{2,5}$

O diagnóstico da NCBDP é determinado pela análise histopatológica e imunohistoquímica da pele e medula óssea. Os achados na anatomopatologia de pele são caracterizados por infiltrado não epidermotrópico, difuso, de uma população de células monomórficas e de tamanho intermediário com cromatina fina, nucléolo de tamanhos variáveis ou ausentes e citoplasmas escassos. A biópsia de medula revela células blásticas atípicas raramente caraterísticas de uma linhagem hematopoiética específica. Para o diagnóstico específico da doença, é necessário a demonstração na imunohistoquímica de CD4 e CD56 e para os marcadores restritos a células dendríticas plasmocitoides, como CD123 e CD303, e negatividade para linhagens linfoide, NK e mieloide. ${ }^{3,6}$ A histopatologia e imunohistoquímica de pele e de medula óssea evidenciaram as características necessárias para o diagnóstico de NCBDP.

A neoplasia de células blásticas dendríticas plasmocitoides apresenta sobrevida média de 12 a 14 meses e em relação ao tratamento, a melhor opção é a quimioterapia com esquemas utilizados para leucemias linfoides e agudas seguida do transplante heterólogo de medula óssea. ${ }^{1,7}$ A maioria dos pacientes apresenta boa resposta inicial ao tratamento, com remissão completa da doença, mas geralmente recorrem dentro dos primeiros 6 meses e a maioria evolui em seguida com rápida progressão da neoplasia.. ${ }^{9} 10 \mathrm{O}$ paciente em questão iniciou tratamento com o protocolo CALGB, não realizou o transplante por motivos pessoais, mas ainda assim apresenta-se em remissão completa da doença mesmo após 17 meses do início do tratamento e 24 meses após o início dos sintomas.

Embora muitas descobertas a respeito da NCBDP tenham surgido nos últimos anos, essa doença ainda representa um grande desafio diagnóstico e terapêutico. Lesões cutâneas podem ser o único sinal de doença e, portanto, os dermatologistas devem estar cientes sobre seu papel fundamental no diagnóstico, evitando assim atraso no início do tratamento. 


\section{REFERÊNCIAS}

1. Gera S, Dekmezian MS, Duvic M, Tschen JA, Vega F, Cho-Vega JH. Blastic plasmacytoid dendritic cell neoplasm: evolving insights in an aggressive hematopoietic malignancy with a predilection of skin involvement. Am J Dermatopathol. 2014;36(3):244-51.

2. Julia F, Petrella T, Beylot-Barry M, Bagot M, Lipsker D, Machet L, et al. Blastic plasmacytoid dendritic cell neoplasm: clinical features in 90 patients. Br J Dermatol. 2013;169(3):579-86.

3. Shi Y, Wang E. Blastic plasmacytoid dendritic cell neoplasm: a clinicopathologic review. Arch Pathol Lab Med. 2014;138(4):564-9.

4. Pagano L, Valentini CG, Pulsoni A, Fisogni S, Carluccio P, Mannelli F, et al. Blastic plasmacytoid dendritic cell neoplasm with leukemic presentation: an Italian multicenter study. Haematologica. 2013;98(2):239-46.

5. Jegalian AG, Facchetti F, Jaffe ES. Plasmacytoid dendritic cells: physiologic roles and pathologic states. Adv Anat Pathol. 2009;16(6):392-404.
6. Facchetti F, Cigognetti M, Fisogni S, Rossi G, Lonardi S, Vermi W. Neoplasms derived from plasmacytoid dendritic cells. Mod Pathol. 2016;29(2):98-111.

7. Ham JC, Janssen JJ, Boers JE, Kluin PM, Verdonck LF. Allogeneic stem-cell transplantation for blastic plasmacytoid dendritic cell neoplasm. J Clin Oncol. 2012;30(8):102-3.

8. Tsagarakis NJ, Kentrou NA, Papadimitriou KA, Pagoni M, Kokkini G, Papadaki H, et al. Acute lymphoplasmacytoid dendritic cell (DC2) leukemia: results from the Hellenic Dendritic Cell Leukemia Study Group. Leuk Res. 2010;34(4):438-46.

9. Feuillard J, Jacob MC, Valensi F, Maynadié M, Gressin R, Chaperot L, et al. Clinical and biologic features of CD4(+)CD56(+) malignancies. Blood. 2002;99(5):1556-63.

10. Kim JH, Park HY, Lee JH, Lee DY, Lee JH, Yang JM. Blastic plasmacytoid dendritic cell neoplasm: analysis of clinicopathological feature and treatment outcome of seven cases. Ann Dermatol. $2015 ; 27(6): 727-37$.

\section{Como citar:}

Pinto KL, Accioly JW Filho, Jorge IF, Avelino AL, Mota TC, Dantas AM, et al. Neoplasia de células blásticas dendríticas plasmocitoides com manifestação cutânea exuberante: relato de caso. Rev Med UFC. 2017 set-dez;57(3):58-61. 